\title{
EL MUSEO ETNOLÓGICO COMO LABORATORIO SOCIOCULTURAL DE LA ALIMENTACIÓN
}

\section{Xerardo Pereiro}

Universidade de Trás-os-Montes e Alto Douro (UTAD), Vila Real, Portugal

Investigador del CRIA (Centro em Rede de Investigação Antropológica).xerardopereiro@utad.pt

Resumen: Presento en este texto una mirada y un breve recorrido sobre la evolución del museo etnológico y la necesidad actual de convertirlo en un laboratorio sociocultural. A lo largo del mismo revisamos la diversidad de tipos de museos etnológicos, sus formas de cambiar y de adaptarse a los nuevos tiempos en este siglo XXI. Finalmente presentamos una propuesta para incluir la alimentación en la misión del museo en su transición a laboratorio sociocultural de la vida humana.

Palabras clave: museos etnológicos, laboratorios socioculturales, museos de la alimentación.

Citar como: Pereiro, X. (2022). "El museo etnológico como laboratorio sociocultural de la alimentación". En: Actas del III Congreso Internacional sobre Patrimonio Alimentario y Museos. 25-26 noviembre, 2021, Valencia, España. pp. 11-27. https://doi.org/10.4995/EGEM2021.2021.14898 


\section{Los museos etnológicos ante su historia}

La institución social "museo etnológico" es una organización socioespacial y sociosistémica donde el patrimonio etnológico se conserva, representa y gestiona. En el museo etnológico podemos analizar la continuidad conceptual entre folclore, cultura tradicional, artes populares, cultura popular, patrimonio etnológico y patrimonio cultural inmaterial. El museo etnológico es por excelencia un lugar para debatir el patrimonio etnológico. A lo largo del texto mostraremos dialécticas y dialógicas pero también aspiraciones y posibilidades de presentación de los patrimonios etnológicos en los museos etnológicos, considerando estos como laboratorios socioculturales de la memoria social y de la alimentación.

El coleccionismo ha estado en el origen de los museos (Riviére, 1989; Alonso Fernández, 1993). El museo es una institución social y cultural que ha servido a lo largo de su existencia como un certificado de antigüedad de países, regiones, territorios y grupos humanos. El origen etimológico de la palabra museo radica en dos acepciones de significado: a) el de templo de las musas y la inspiración, y b) el de lugar o edificio destinado al estudio de las humanidades, las ciencias y las artes, con biblioteca, salas de docencia, estudio, zoológico, jardín botánico, alojamiento para profesores, comedor, observatorio y anfiteatro (Riviére, 1989; Nabais, 1984). Por lo tanto, en su origen etimológico e histórico griego hay que diferenciar entre el museo como colección o templo de materiales culturales e históricos, y el museo como centro de investigación, comunicación, encuentro, debate y docencia.

Otro antecedente de la institución museo lo situamos a finales de la Edad Media y a inicios del Renacimiento, con la creación de los gabinetes de curiosidades, gabinetes del mundo, cámaras de maravillas, galerías de los reyes, o "tesoros" de reyes, aristócratas y burgueses (ej. la galería del papa Sixto IV en Roma). Sus contenidos pueden ser definidos como artísticos, naturalísticos o etnográficos y representaban una mirada occidental del otro no europeo (Riviére, 1989). Cada una de sus piezas adquirió la capacidad de representar y conocer el mundo (Iniesta, 1994) pero también proyectaban la visión del mundo de su coleccionador.

En el siglo XIX, con la llegada de la revolución burguesa e industrial, los museos nacen como instituciones modernas, muchos de ellos ligados al estado-nación. Su función fue entonces la de convertirse en referentes identitarios de las nuevas naciones-estado, educar a sus ciudadanos y crear la nación de ciudadanos y no ya de súbditos como en la época anterior (ej. absolutismo). El museo nace como un aparato simbólico y mítico de la nación, que pasa a ser el sujeto y objeto colectivo del museo. El museo va a vehicular un discurso ideológico de las identidades de un grupo social étnico-nacional y tendrá la misión de concientizar y educar al pueblo. Pero paradójicamente, e inicialmente, tendrá que utilizar elementos materiales y culturales de la monarquía y de la aristocracia, contra las cuales se luchó en la Revolución Francesa.

Es entonces que nace el concepto de exposición temporal, el de exposición individual, y el de conservación de objetos como campo de especialización y formación en el museo (Iniesta, 1994; Valdés Sagues, 1999). En esta época decimonónica nacen varios tipos de museos especializados: de arte, de arqueología, de ciencias naturales, de historia, de ciencia y técnica, de etnología, etc. Y es también en ese contexto que se definen las funciones fundamentales del museo: coleccionar, crear, investigar, educar, reconocer y proteger los patrimonios culturales.

A inicios del siglo XX se produce un cambio en la institucionalización de los museos. Se regionalizan, se redefinen, se descentralizan y representan identidades locales y regionales. Un 
ejemplo son los “Heitmatmuseen” alemanes, museos plurisciplinares del terruño. En el año 1937 se crea el Museo del Hombre en París, hoy desaparecido y reabierto en el 2016 como Museo du Quai Branly - Jacques Chirac (http://www.quaibranly.fr/es/), con una función de entender y respetar las culturas del mundo. A mediados del siglo XX, los museos se vuelven más especializados, dando más importancia a la dinamización de actividades que a las colecciones de objetos y materiales. Es así que se elaboran los kits o mini exposiciones itinerantes, las maletas museo (Riviére, 1989).

Después de la segunda guerra mundial, en el año 1947 nace el ICOM (International Council of Museums), quien rápidamente se preocupa por definir científicamente el concepto de museo:

\begin{abstract}
"The word "museums" includes all collections open to the public, of artistic, technical, scientific, historical or archaeological material, including zoos and botanical gardens, but excluding libraries, except in so far as they maintain permanent exhibition rooms." (ICOM -Comisión Internacional de Museus-, 1946; citado en Alonso Fernández, 1993: 28).

"The word of museum here denotes any permanent establishment, administered in the general interest, for the purpose of preserving, studying, enhancing by various means and, in particular, of exhibiting to the public for its delectation and instruction groups of objects and specimens of cultural value: artistic, historical, scientific and technological collections, botanical and zoological gardens and aquariums. Public libraries and public archival institutions maintaining permanent exhibition rooms shall be considered to be museums." (ICOM, 1956; citado en Alonso Fernández, 1993: 28)
\end{abstract}

En el año 1958, la UNESCO reconoce el museo como una institución educativa formal y complementaria de la escuela. Un poco más tarde aparecerán los ecomuseos, que recuperan la vieja idea de los museos al aire libre escandinavos, y los museos integrales que unen diferentes tipos de patrimonios culturales y contenidos (Mesa de Santiago de Chile de 1972), teniendo en cuenta el desarrollo social de las comunidades. Igualmente será en ese momento que nacen los museos de sociedad, los museos de comunidad (ver las obras de Mario Vázquez e Iker Larrauri en México) y el movimiento internacional de la nueva museología (MINOM). El MINOM se centrará más en los problemas de la comunidad que en los problemas del objeto museológico, e implicará un cambio de mentalidad de los museólogos, pero también de lenguaje, funciones y contenidos (Alonso Fernández, 1999)

La nueva museología tiene orígenes discutibles, pero muchos consideran que la Declaración de Quebec de 1984 fue su punto de partida oficial. En esa declaración definen, frente a lo anterior, la interdisciplinaridad del museo, la museología social y el desarrollo comunitario como ejes del museo. Un año más tarde, en 1985 se creará en Lisboa el MINOM (Movimiento Internacional de Nueva Museología), un movimiento más preocupado por responder a las necesidades sociales de las comunidades que se encuentran en el contexto del museo, por empoderar y dar protagonismo la gente, y menos por hacer de los museos receptores del discurso y prácticas del museo. Participación, crítica, conceptos (en vez de objetos) y consciencia reflexiva de la realidad son palabras de orden para la nueva museología.

En el año 1974 la museología se imparte como disciplina académica en 160 universidades (Riviére, 1989), y el ICOM, en su $11^{\mathrm{a}}$ asamblea general celebrada en Copenhague (Dinamarca), definirá el museo de esta forma:

“(...) es una institución permanente, no lucrativa, al servicio de la sociedad y su desarrollo, abierta al públi$\mathrm{co}$, que adquiere, conserva, investiga, comunica y principalmente expone los testimonios materiales del Hombre y su medio ambiente, para fines de estudio, educación y placer." (ICOM, 1974, título 2, artículo 3, citado en Alonso Fernández, 1993: 31) 
En ese mismo año se incluyeron en la definición de museo: a) los institutos de conservación, las galerías de exposición de archivos y bibliotecas; b) los lugares y monumentos arqueológicos, etnográficos y naturales, y también los sitios y monumentos históricos; c) Los jardines botánicos, los zoológicos y los acuarios.

En el año 1983 el ICOM (XIV Asamblea en Londres), añade a la categoría museo los parques naturales, arqueológicos e históricos, y también los centros científicos y planetarios. Desde entonces, el museo ha evolucionado en varios sentidos, se ha mercantilizado, se ha turistificado y se ha espectacularizado (Valdés Sagues, 1999). Además, ha cambiado su discurso científico y político-identitario, de un museo nacional, imperial y colonial hemos pasado a una idea de museo intercultural, transnacional, cosmopolita y postcolonial. De un museo temático y especializado estamos transitando cara a un museo de las convergencias y a nuevas especializaciones (ej. los museos de la alimentación), del museo escaparate al museo interactivo, del museo visual al audiovisual y al museo de los sentidos, emocional, multisensorial y digital. Estos cambios han supuesto desafíos en el modelo de gestión de la institución-museo que no todos los museos han asumido. Las adaptaciones, resistencias, ritmos de cambio y progresos han sido diferentes y desiguales en los contextos de aplicación y desarrollo. Así, por ejemplo, muchos museos locales y regionales se han convertido en museos de la historia local en la forma de "congeladores" de la memoria.

De acuerdo con los nuevos estatutos del ICOM, aprobados por la $22^{\mathrm{a}}$ asamblea celebrada en Viena el 24 de agosto del año 2007:

"El museo es una institución permanente sin fines lucrativos, al servicio de la sociedad y de su desarrollo, abierta al público, que adquiere, conserva, investiga, comunica y expone el patrimonio material e inmaterial de la humanidad y de su medio envolvente con fines de educación, estudio y deleite." (http:// icom-portugal.org/2019/09/10/sobre-a-proposta-da-nova-definicao-de-museu/ ).

En la conferencia trienal del ICOM, realizada en Milán en el año 2016, fue designada una nueva comisión permanente para estudiar y presentar una nueva definición de museo, que tenía como objetivo ofrecer una perspectiva crítica sobre la vigente definición y crear otra con alcance internacional. Después de tres años de trabajo y 269 propuestas (https://icom.museum/es/ news/la-definicion-del-museo-la-columna-vertebral-del-icom/ ), en el año 2019 se presentó en la conferencia de Quito (Japón) una nueva definición de museo, que finalmente no fue aprobada por falta de consenso, pero que reproducimos aquí por su gran interés para el debate:

\footnotetext{
"Los museos son espacios democratizantes, inclusivos y polifónicos, orientados al diálogo crítico sobre los pasados y los futuros. Reconociendo y lidando con los conflictos y desafíos del presente, detienen, en nombre de la sociedad, la custodia de artefactos y especímenes, por ella preservan memorias diversas para las generaciones futuras, garantizando la igualdad de derechos y de acceso al patrimonio a todas las personas. Los museos no tienen fines lucrativos. Son participativos y transparentes; trabajan en cooperación activa con y para comunidades diversas en la recogida, conservación, investigación, interpretación, exposición y profundización de los varios entendimientos del mundo, con el objetivo de contribuir para la dignidad humana y para la justicia social, la igualdad global y el bienestar planetario." (https://icom. museum/en/news/icom-announces-the-alternative-museum-definition-that-will-be-subject-to-a-vote/)
}

Llegados a las primeras décadas del siglo XXI podemos referirnos a un estado de "museomanina" (Segalen, 2003: 46), es decir, una sobreabundancia de museos por todo el mundo. Un museo que ya no es simplemente un almacén o exposición de patrimonios culturales, sino un medio de desarrollo económico y turístico. Y en su diversidad encontramos museos oficiales con un discurso dominante, museos críticos que actúan como instrumento de denuncia y de 
inversión de las categorías y estereotipos negativos (ej. Museos amerindios del Quebec), museos postcoloniales, museos como nueva fábrica de identidades, museos creativos, educativos y divertidos, etc.

El museo se ha popularizado y convertido en el siglo XXI en un centro de exposición del conocimiento, lugar de encuentro social, comunicación, investigación y educación permanente, y no solamente en un lugar erudito para iniciados (ej. investigadores). De la crítica al museo pasamos al museo crítico (cf. Lorente, 2006), y de tener espectadores a públicos y visitantes empoderados, de mostrar la homogeneidad y la unidad a representar las desigualdades, la diversidad, los conflictos, las dialécticas, las dialógicas, las aspiraciones y las posibilidades de desarrollar diversos modos de vivir. Algunos ejemplos de estos procesos de cambio de paradigma en la museología, especialmente de un museo colonial a un museo intercultural, son:

- Museo de Historia de la ciudad de Helsinki: https://finland.fi/es/arte-y-cultura/la-historia-de -helsinki-vive-el-renovado-museo-de-la-ciudad/

- Museo de las relaciones rotas: https://brokenships.fi/

- Ellis Island National Museum of Imigration (1989- ): https://libertyellisfoundation.org/ immigration-museum

- Museo de la Historia de la Inmigración de Catalunya (2004- ): http://www.mhic.net/?lang=es

- Museo de Amberes (Bélgica): https://www.mas.be/en

En relación con estos cambios que se están a producir en los museos del siglo XXI recomendamos ver y analizar la entrevista con Jette Sandahl (ICOM) (Ver en https://www.youtube. com/watch?v=e6eROC9Lk0A). Ella es la fundadora de dos museos innovadores, uno de ellos el museo de la mujer de Dinamarca, el otro el museo de las culturas del mundo en Gotemburgo (Suecia), y según ella los museos en el siglo XXI deben descolonizarse y adoptar el lenguaje, las necesidades y perspectivas propios de este siglo. Lo cierto es que la institución museo puede ser vista como un campo de tensión entre la conservación y el cambio, entre la permanencia y la innovación.

\section{Museología, museografía y museos}

Como hemos visto, la definición de museo ha estado en redefinición permanente a lo largo de su historia, pero mantiene y conserva algunas ideas clave, como la de diferencia del museo (institución) con una simple colección. El estudio del museo corresponde a la museología (Riviére, 1989; Alonso Fernández, 1993; Nabais, 1984). La museología es un campo de estudios multidisciplinar del museo que trata de los principios filosóficos, epistemológicos y teóricos que orientan la práctica de la museística, pero también su papel en la sociedad y sus funciones sociales (ej. conservación, educación, investigación, comunicación...). La museología liga el continente con el contenido, el edificio con el proyecto museológico, y produce la planificación del museo.

La museología no debe ser confundida con la museografía, que es el conjunto de técnicas y prácticas de aplicación de la museología. La museografía es más ejecutora y trata de los aspectos administrativos y técnicos del museo (ej. humedad relativa de las salas, identificación de las obras, iluminación, seguridad, etc.). La museografía está al servicio de la museología y ayuda a convertir el museo en espejo, ventana y escaparate de la cultura y del patrimonio cultural en 
general. El museo debe ser un espejo de las comunidades y sus identidades plurales, y también una ventana para observar y pensar el mundo, pero también un escaparate para revernos y compararnos reflexivamente con otros (Riviére, 1989).

En este sentido, el museo es cada vez más un instrumento de reflexión, educación, entretenimiento y comunicación, y un laboratorio sociocultural de todo eso, también de la alimentación (eje central de la vida de la gente), lo que complica la propia identidad y función del museo. Los museos son un instrumento de reproducción simbólica de la sociedad (Iniesta, 1994), creadores de imágenes culturales colectivas y una fábrica de representación de las identidades. Pero lo cierto es que hay una gran diversidad de museos.

\section{La variedad y la diversidad de museos etnológicos}

Los museos de antropología, etnológicos u "etnográficos", a los cuales los antropólogos siempre han estado ligados, se pueden definir por sus contenidos, por el perfil científico de sus profesionales, por sus discursos y prácticas museológicas y antropológicas, pero también por su relación con sus comunidades y públicos. El museo antropológico u etnológico suele anteponer el interés cultural al cronológico en la presentación de las obras, objetos e ideas. El mismo ha estado anteriormente ligado al concepto de gabinete de curiosidades y al de museo de "artes y tradiciones populares". La historia del museo etnológico ${ }^{1}$ es la de un museo dedicado a la presentación de objetos del pasado por medio de una pintura de las costumbres populares, la representación de lo considerado auténtico, rural, tradicional, campesino, marinero, popular, lo que se pierde o desaparece... Pero esto ha ido cambiando con el paso del tiempo como hemos indicado más arriba.

Es pertinente diferenciar aquí entre antropología museológica, que es la antropología del y para el museo, hecha por profesionales de la antropología desde fuera del museo; y la museología antropológica, realizada por museólogos que se encuentran formados en antropología y que aplican antropología en el museo antropológico o etnológico, u otros. La museología antropológica ha experimentado varios cambios a lo largo de su historia que podemos resumir por medio de un breve análisis de algunas tipologías de museos (Llopart, 1994: 10-13; Calvo Serraller, 1996):

1. Gabinetes de curiosidades: colección de materiales exóticos guardados en arcas especiales. Ejemplo: El de Carlos III en el Palacio Goyeneche de Madrid (1776).

2. Museos de historia natural. Exhibieron humanos a principios del siglo XX, como una especie más de los ecosistemas. Siguieron un discurso de la antropología física vinculada a la antropología cultural. Consideraron los humanos como animales, eligiendo los que pensaban "primitivos", algo criticado y cuestionado después por antropólogos y museólogos por su racismo y xenofobia implícita. Ejemplos: Museo de Historia Natural de New York, Museo Nacional de Etnología (Madrid).

3. Museos de artes exóticas. A partir de los años 1920, algunos museos exhiben piezas como si fueran obras de arte y sin tener en cuenta el modo de vida de la sociedad que representan.

\footnotetext{
Los museos de antropología más antiguos de Europa son: el Museo de Leyden (1831), el Museo de Berlín (1873), el Museo Pitt Rivers, de Oxford (1874), el Museu del Hombre, de Paris (1878) y el Frilandamuseet a Sorgenfri, de Copenague, (1890), como indica Llopart (1994).
} 
Presentan lo que denominan "arte primitiva", especialmente africana. Ejemplo: algunas colecciones del Museo Etnológico de Barcelona.

4. Museos interdisciplinares. Dedicados a la historia, la tecnología y la cultura de un territorio concreto. Exhiben permanentemente testimonios materiales de la vida y del trabajo campesino (indumentaria, objetos familiares, mobiliario, etc.). Ejemplos varios en museos locales.

5. Museos escolares. Museos como instrumentos educativos para niños, jóvenes y mayores. Educan en la convivencia y en la tolerancia. Ejemplos: Museo Horniman's (Londres).

6. Museos de lugar real o museos de la memoria. Son construidos en zonas de conflicto social y represión. Ejemplo: Museo del Campo de Concentración de Mauthausen (Alemanha), Museo de la Isla de Staten (Nueva York).

7. Museos al aire libre. Reconstruyen in situ actividades artesanales e industriales con la teatralización de personas reales. Ejemplos: Nordiska Museet (Skansen-Estocolmo, 1891), Museo al aire libre de Arnhem (Holanda).

8. Ecomuseos. De origen francés, están vinculados con la política francesa de desarrollo rural iniciada en el año 1963. Son museos de territorio con interpretación de los patrimonios culturales en su propio contexto.

Claro está que las tipologías de museos no son los propios museos, y éstas divergen en las variables utilizadas para definir los diferentes tipos y categorías, pero ayudan a explicar y a comprender estos en su diversidad y cambio. El antropólogo portugués Paulo Castro Seixas (1997) consideró la existencia de tres tipos de museos etnológicos:

1. El museo etnográfico u etnológico clásico, de edificio cerrado, de espacio "caverna", centrado en los objetos, con las funciones de almacén y laboratorio muy destacadas, con mayor atención al pasado y a un visitante pasivo que recibiría un mensaje ilustrado de forma linear. Coincidiría con el concepto de museo cementerio o museo anticuario del que hablan Prat y Comelles (1992), en el cual la finalidad última es coleccionar objetos, no sin descontextualizar bastante estos objetos fuera de su nicho sociocultural original. Aquí la antropología funciona como una especie de arqueología museu (Pais de Brito, 2006). Este tipo de museo podía seguir una clasificación y representación cultural con criterio comparativo tipológico, como por ejemplo el Museo Pitt Rivers de Oxford, o una clasificación etnológica-geográficaterritorial, como, por ejemplo, el Museo Etnográfico de Berlín.

2. El museo de sitio, al aire libre o ecomuseo, promovido por la nueva museología. Éste se caracterizaría por ser abierto, territorial, de la población, de la identidad y del testimonio de una memoria, menos centrado en edificios y con más atención a los valores del presente. El visitante de este modelo de museo es más activo y participante, y el proyecto museológico no es solamente realizado por especialistas o peritos, sino que suele ser una propuesta con integración de la comunidad en la interpretación de sus patrimonios culturales. Este modelo de tipos de museo es resultado de una crisis de la representación museológica de la cultura.

3. El museo de ruptura o museo dialógico es un modelo en el cual el visitante es un agente activo del museo, ya más interactivo, dialógico y multisensorial. Lo que importa aquí no es el mensaje linear, sino el proceso de descubrimiento guiado y orientado. Es un museo de 
las personas y para las personas, en el cual el objeto no es tan importante, sino un pretexto para hablar de la vida de la gente y sus ideosistemas. Este modelo de museos sigue una orientación más polifónica y además escucha a la gente y no solamente habla.

Otra buena tipología de referencia para comprender los museos etnológicos es la que creó el antropólogo catalán Xavier Roigé (2007):

a. Los museos al aire libre (Johnson e Thomas, 1992): Skansen (Suecia), Beamish (Reino Unido), Nederlans Openluchtmuseum (Países Bajos).

b. Los ecomuseos (Riviere, 1989; Walsh, 1992; Davis, 1999; Fernández de Paz, 2003; Pereiro, 2009). Estos presentan concepciones y objetivos diferentes de los anteriores. Promovidos por la "nueva museología" en los años 1970, y definidos por Rivière como un museo de los humanos y de la naturaleza.

c. Los economuseos, que reconstruyen unidades ecológicas preexistentes y no desplazan edificios y objetos de lugar (Museu Ferrari en Módena - Itália: https://musei.ferrari.com/en/ modena).

d. Los museos regionales y los museos de síntesis, que pretenden realizar una presentación general de una sociedad o comunidad en sus aspectos geográficos, sociales y culturales de una forma sintética y de acuerdo con el modelo monográfico o propio de los estudios de comunidad. Muchos de ellos parecen clones con el mismo esquema expositivo: el medio, la historia, la cultura tradicional.... La renovación de contenidos, actividades y puntos de vista son escasos en ellos. Buenos ejemplos de museos que se encuadran en este tipo son: el "Musée Dauphinois", el museo de la "Civilisation de Québec" y el "d’Ethnographie de Neuchâtel".

Otro tipo importante de museo etnológico es el de economuseo (Simard, 1989, 1991; Roigé i Ventura, 2007). El economuseo ha sido inventado en Canadá por Ciril Simard, y es un concepto que articula economía y cultura, empresa y representación cultural en un espacio que sirve para que el patrimonio cultural se gane la vida, es decir, genere financiamiento propio para el museo. Los economuseos mercantilizan la idea de museo, pero también reflexionan sobre el papel del patrimonio etnológico en el desarrollo social, económico y comunitario.

Por otro lado, autores como Hooper-Greenhill (2000) refieren al postmuseo, que Marstine (2006) ha definido como:

"El post-museo articula claramente sus agendas, estrategias y procesos de toma de decisiones y los re-
evalúa continuamente, reconociendo así la política de representación; el trabajo del personal del museo
nunca se naturaliza, sino que se considera que contribuye a estas agendas. El post-museo busca acti-
vamente compartir el poder con las comunidades a las que sirve, incluidas las comunidades de origen.
Reconoce que los visitantes no son consumidores pasivos y conoce a sus constituyentes. En lugar de
transmitir el conocimiento a una audiencia masiva esencializada, el post-museo escucha y responde
con sensibilidad, ya que alienta a diversos grupos a participar activamente en el discurso del museo. No
obstante, en el post-museo, el museólogo no es un mero facilitador, sino que asume la responsabilidad
de la representación cuando se dedica a la investigación crítica. El post-museo no escapa a los proble-
mas difíciles, sino que se expone al conflicto y la contradicción. Afirma que la institución debe mostrar
ambigüedad y reconocer múltiples identidades en constante cambio. Lo más importante es que el post-
museo es un sitio desde el cual se pueden corregir las desigualdades sociales... el post-museo puede
promover el entendimiento social." (Marstine, 2006: 19).

En esto se despolitiza la diferencia cultural, se practica un multiculturalismo lúdico, la interculturalidad y de la lógica de la investigación científica se pasa a una lógica de la comunicación 
(visitantes y públicos). Se adopta una perspectiva de diversidades culturales locales, de la globalización, del cosmopolitismo, de una historia colonial crítica, de la mezcla y el hibridismo cultural, del postmulticulturalismo y de la descolonización. En estos nuevos museos o viejos museos renovados, la cultura es algo más que un inventario de objetos, se descolonizan los museos y sus representaciones, y los museos se vuelven más críticos, contestatarios y disidentes. Ejemplos internacionales de esto último que afırmamos son los siguientes:

- Quai Branly (París, 2006- ): http://www.quaibranly.fr/fr/expositions-evenements/au-musee/ expositions/

- Museo de las culturas (Basilea, Suiza, 2010- ): https://www.mkb.ch/en/programm.html

- Museo de las Culturas del Mundo, Rautenstrauch-Joest (Colonia, Alemania, 2011- ): https://museenkoeln.de/rautenstrauch-joest-museum/Visitors

- Linden-Museum Sttugart (2011-): https://www.lindenmuseum.de/en/

- Museo Real de África Centrla (Tervuren, Bélgica, 2011- ): http://www.africamuseum.be/

- Museo de las culturas del mundo (Gotemburgo, Suecia, 2004- ): http://www. varldskulturmuseerna.se/en/varldskulturmuseet/

- Museo de los Trópicos (Amsterdam, Holanda): https://www.tropenmuseum.nl/en

- Tenement Museum (New York) - Museo de Inmigración: https://www.tenement.org/

\section{El museo etnológico como laboratorio sociocultural (también de la alimentación)}

Referirnos al museo etnológico como laboratorio es destacar su función social investigadora, es decir, a como el museo etnológico debe cumplir un papel social de centro de investigación social, de pensamiento y de dinamización comunitaria (cf. Pereiro y Vilar, 2002). En la perspectiva de Riviere (1989) esto es inexcusable, especialmente en los ecomuseos, que en su perspectiva deben ser laboratorios, conservatorios y escuelas. Como laboratorio, el museo etnológico debe tener en cuenta:

a. Una exposición permanente sobre la historia de la comunidad a quien sirve.

b. Equipamientos: centro de documentación, centro de trabajo, hemeroteca, fototeca y videoteca.

c. Atelier técnico de conservación

d. Almacenes.

e. Salas de exposiciones temporales.

f. Auditorios.

g. Talleres para estudiantes.

h. Una red de caminos para visitar las diferentes antenas, polos o secciones.

i. Alojamiento para investigadores.

j. Acceso a internet. 
Podemos considerar el museo etnológico como un laboratorio de patrimonio etnológico (ej. alimentar). Lo cierto es que la gran "natalidad" de museos etnológicos ha producido una relación compleja entre el museo etnológico y sus patrimonios etnológicos. Basándonos en la obra de la antropóloga Montserrat Iniesta (2002), podemos referirnos a cuatro tipos de relaciones:

a. Patrimonio etnológico dentro de los museos. Esta relación tiene como base la idea de que tenemos que conservar todo o lo máximo posible, y se expresa en un síndrome de arca de Noé.

b. Patrimonio etnológico fuera de los museos "almacén". En este caso, el patrimonio etnológico se encuentra organizado, presentado e interpretado fuera del tradicional museo-edificio (ej. en un ecomuseo), por ejemplo, a través de antenas o polos del propio museo central en los cuales se contextualizan los patrimonios culturales.

c. El museo como patrimonio etnológico. El museo se valoriza como arquitectura, edificio o espacio capaz de dinamizar socioeconómica y políticamente sin gran contenido patrimonial etnológico. El envoltorio es sobrevalorizado en relación con el contenido.

d. Elmuseo sin patrimonio etnológico, resultado de la crisis patrimonial (todo es patrimonializable), donde se convierte en centro de investigación y documentación, pero también en centro de actividades culturales y educativas. Aquí se da menos importancia al contenedor y a sus colecciones y más a la plantilla de trabajadores- investigadores del museo, que reconocen los procesos de patrimonialización y ponen sus conocimientos e investigaciones al servicio del bien público.

Los museos etnológicos son una forma de producción de patrimonio etnológico, al cual dan una segunda vida (Kirshenblatt-Gimblett, 1998, 2001), pero también pueden ser considerados como centros de interpretación cultural y laboratorios de investigación sociocultural donde la comunicación (ver https://www.visitorstudies.org/) se vuelve muy importante (Lumley, 1988:; Hooper-Greenhill, 1998). Los museos etnológicos tienen el desafío de ser algo más que una lección de cátedra de un museólogo o antropólogo.

Según Claude Lévi-Strauss (1973) el museo etnológico debe ser la prolongación del trabajo de campo antropológico, un museo laboratorio o un museo seminario de investigación y debate. Pero, en realidad, son muchos aun los que piensan el museo etnológico como un frigorífico donde congelar y fosilizar elementos culturales. Esa versión del museo como panteón lleva a una cristalización de objetos e identidades, presentadas como fijas, permanentes e inmutables. Ello es debido en parte a que en muchos contextos museológicos la teoría antropológica contemporánea penetra muy lentamente y a que la presencia de antropólogos con suficiente poder es relativamente baja.

La museología crítica de Jacques Hainard (1989) ha criticado la idea de que el objeto debe ser central en el museo. La alternativa es que los objetos estén al servicio de la idea. El museo no es un libro de texto o una tesis doctoral y el museo etnológico no debe presentar objetos como si fuesen museos de arte. De acuerdo con la propuesta de Xavier Roigé (2007), el museo etnológico debe dejar de ser un templo de nostalgia, conservatorio de diferencias culturales o cementerios para llorar la diversidad perdida. El museo etnológico tiene que ser un lugar de preguntas, debates y democracia cultural, de explorar el presente, el pasado y el futuro (Pomian, 1996). 
El museo etnológico (ej. de la alimentación) debe convertirse en un laboratorio sociocultural crítico en el cual se exploren nuevos lenguajes expositivos (ej. diversas subjetividades y autorias), nuevos temas, nuevas voces críticas, perspectivas cuestionadoras y disidentes, miradas descolonizadoras, estrategias de integración social y oportunidades para la participación social y cohesión, innovaciones tecnológicas y didácticas que permitan crear nuevos marcos de convivencia. Además, debe ser más interdisciplinar y menos mausoleo (Witcomb, 2003). El museo etnológico debe crear una complicidad con su sociedad local hasta el punto de que ésta se sienta orgullosa del museo (Carvalho, 2011) y en ese sentido la alimentación es un nexo de unión humana y de posibilidades inmensas de cooperación entre el museo y la sociedad. Además, el museo etnológico como laboratorio sociocultural debe garantizar recursos, y mantener un equilibrio entre la dirección del museo, el turismo y la comunidad local.

\section{El museo de la alimentación como laboratorio sociocultural}

Aquí hay que diferenciar entre los museos etnológicos que tratan parcialmente la alimentación como uno de sus ejes temáticos de reflexión y comunicación, y los museos temáticos de la alimentación o de los procesos alimentares como eje central discursivo y experiencial. Entre los primeros tenemos un buen ejemplo en el Museo de la Pesca de Palamós (Catalunya) (ver: www.museudelapesca.org), dirigido por Miquel Martí. Este museo envuelve la comunidad local y los visitantes por medio del uso de las memorias sociales y del patrimonio cultural marítimo (ej. paseos en barcos pesqueros, tertulias de taberna, etc.). Tiene una exposición permanente sobre el pescado como alimento, que atrae, enseña y emociona a muchos visitantes.

Los museos de la alimentación se centran en la comida, bebida y alimentos como eje temático de su discurso museológico. Ellos han aparecido con fuerza en las últimas décadas y han servido como atractores de muchas regiones y localidades, ello es debido a que la alimentación es un tema transversal a toda la humanidad, muy inserida en los cotidianos de la gente y que motiva mejor el acercamiento de los públicos porque es un tema muy popular. Por otro lado, las clases medias occidentales utilizan la alimentación y sus refinamientos como una estrategia temática de afirmación de clase y de estatuto, la alimentación es un asunto de exhibición, distinción y presunción social (ej. los vinos y sus museos). Los ejemplos de museos de alimentación son muchos y diversos, pero por poner un ejemplo me gustaría subrayar el museo del chocolate de Barcelona (ver http://www.museuxocolata.cat/) promovido por el gremio de pastelería de la ciudad capital catalana.

Proponer que los museos de alimentación sean laboratorios socioculturales críticos significa que deben cumplir funciones sociales investigadoras, para lo que se necesitan recursos humanos y materiales específicos según la orientación que se le quiera dar. Como vimos esta es una vieja idea anclada ya en la mente y obra de museólogos como Riviere (1989) y otros. En cuanto laboratorio sociocultural, el museo de la alimentación debe tener idealmente lo siguiente:
a. Los profesionales con los que cuenta.
b. Los voluntarios con los que puede contar.
c. Un consejo científico-técnico.
d. La comunidad y el territorio próximos. 
e. El trabajo en red con otros museos.

f. La producción-distribución-consumo de alimentos.

g. El viaje de los alimentos.

h. La lucha contra el hambre.

i. La comida como placer social.

j. Un programa de actividades que envuelva a la comunidad local.

k. Una exposición permanente sobre temáticas de alimentación y desde una perspectiva integral.

I. Salas de exposiciones temporales.

m. Equipamientos para investigación interna y externa: centro de documentación, centro de trabajo, hemeroteca, fototeca y videoteca digitales.

n. Una cocina y una sala de prueba de alimentos para actividades educativas comunitarias.

o. Un laboratorio de análisis sensorial si es posible.

p. Restaurante - café - bar como espacio de encuentro intercultural alrededor de la comida y la bebida.

q. Algún espacio para almacén.

r. Sala de videoconferencias.

S. Auditorios para reuniones y encuentros.

t. Talleres para estudiantes.

u. Una red de caminos para visitar las diferentes antenas, polos o secciones del museo.

v. Alojamiento para investigadores visitantes si es posible.

w. Acceso a internet.

Siendo conscientes de que muchos museos de la alimentación generan o pueden generar sus propios recursos sin necesidad de financiamiento público, lo cierto es que muchos tienen recursos limitados y se han mercantilizado en su gestión y misión. Y es en función de esos recursos que cada museo hace y puede hacer su propuesta museológica, sin descuidar que la comunicación y la creación de lazos son un capital para el museo. El museo de la alimentación es un excelente cronotopo para cruzar enfoques de investigación biotecnológicos con enfoques socioculturales y humanísticos, más aún si conseguimos relacionar este con las universidades y centros de investigación alimentar. Y más allá de su mercantilización y mercantilismo, por veces inevitables por la falta de apoyo público, estos deben tener una función social, educativa y transformadora de los modos de vida de la gente hacia un mundo más habitable, sostenible, justo y solidario, en el cual la palabra hambre sea un mal recuerdo del pasado. Además, los museos de la alimentación son lugares excelentes para educar en valores que defiendan una alimentación saludable. Y es más, los museos en general deberían de tener en cuenta como la alimentación en general (ej. los restaurantes de los museos) es un tema que atrae, engancha y motiva el uso de los museos por locales 
y visitantes, como es bien el caso del museo de las culturas del mundo en Gotemburgo o el de etnología en Estocolmo. En ellos la nutrición se une con la alimentación, el conocimiento cultural con el placer de comer y beber, pero también unas generaciones con otras, y los locales con los visitantes por medio de un laboratorio social y cultural de la comida como eje vital.

\section{Propuesta de guion de trabajo para convertir el museo etnológico (de la alimentación) en laboratorio sociocultural}

Como propuesta de reflexión-trabajo que ayude a transitar el museo etnológico para un museo laboratorio sociocultural proponemos tener en cuenta los siguientes aspectos:

Datos básicos del museo

- Nombre:

- Dirección:

- Ubicación en el mapa:

- Número de teléfono:

- Correo electrónico:

- Web:

- $\quad$ Tipo de entrada (gratis, pagado, ¿cuánto es el billete?)

- Tipo de museo: público / privado / sociedad civil - organización / comunidad

- Institución que gestiona el museo:

- Presupuesto anual del museo:

- Fuentes de ingresos del museo (públicas, privadas, metate, asociadas, entradas...):

- Historia y memorias del museo:

- ¿Quién lo diseñó? Ej. arquitecto. ¿Ha teniendo en cuenta la orientación museológica?:

- Descripción de las instalaciones (por ejemplo, recepción, salas de exposiciones, tienda, oficinas, restaurante...):

- Funciones del museo (colección, conservación, exposición, educación, investigación...):

- Describir las colecciones y contenidos del museo:

- Tipos de patrimonio cultural que integra:

- Tipo de exposiciones y programas:

- Actividades que lleva a cabo:

- ¿Servicio educativo?

- Tienda de souvenirs - recuerdos? ¿Qué tipo de souvenirs se venden más y cuánto facturan anualmente? ¿Han cambiado con el tiempo? ¿Por qué? 
- ¿Tiene visitas guiadas? ¿Qué pasa con las audioguías?

- ¿Ofrece un tour virtual por Internet?

- ¿Tiene un guión braille para los ciegos?

- ¿Qué tan accesible es para las personas con movilidad reducida?

- ¿Tienes un libro de visitas en papel o en digital? (Analizar su contenido y mensajes).

- ¿Tiene un mapa - planta del museo?

- ¿Tiene algún folleto?

- ¿Trabaja en red con otros museos?

- ¿Qué asociaciones tiene con otras instituciones y organizaciones?

Información sobre la dirección del museo y su visión del mundo

- Nombre:

- Género:

- Fecha y lugar de nacimiento (naturalidad):

- Dirección o lugar de residencia:

- Nacionalidad:

- Edad:

- Estado civil:

- Número de hijos:

- Área de formación:

- Percurso educativo - nivel educativo

- Idiomas hablados

- Orientación religiosa - credencial: (por ejemplo, católico, agnóstico, ateo,...)

- Orientación política: (derecha, centro, izquierda, apolítica, apartidista, otras...)

- Ocupaciones y profesiones anteriores:

- ¿Información de migración personal? (Historia residencial y lugares donde recuerdas haber vivido, en qué lugares, en qué barrios, fechas de cambios y razones, personas que compartieron la casa contigo, cambios temporales, destinos y razones,)

- ¿Qué tipo de contrato tiene actualmente?

- ¿Qué países conoce?

- ¿Qué museos conoces y cuáles están inspirados en el museo que diriges?

- ¿Qué ha hecho y ha aprendido de trabajos anteriores? 
- Si ha cambiado de trabajo - actividad, ¿cuáles son las razones?

- ¿Qué opina del territorio donde se encuadra su museo?

- ¿Qué opinión tiene del papel de los museos en su región y su relación con el turismo?

- ¿Cuáles son sus objetivos a corto, mediano y largo plazo?

- ¿Te gusta lo que haces? ¿Te sientes satisfecho?

- ¿Cómo se ve el turismo en la región?

- ¿Qué fortalezas tenemos? ¿Qué debilidades encuentras?

- ¿Cómo podría mejorar el museo?

- ¿Cuál es la relación entre el turismo y el museo?

- ¿Qué tipo de turistas recibe?

- ¿Qué visitantes atraer?

- ¿Qué ofrecen a los visitantes?

Información sobre el público del museo, visitantes y usuarios

- ¿Hay un registro de visitantes?

- ¿Cuál es la evolución del número de visitantes? (número, perfil social, tipos...)

- Distribución anual, mensual y semanal de visitantes:

- Origen, nacionalidad, región, género, edad, profesión, clase... de los visitantes y usuarios del museo.

- ¿Cuál es la diferencia y relación - ratio entre los turistas/residentes locales en las visitas al museo?

- ¿Cuánto dura la visita debido a la diversidad de visitantes?

- ¿Cuánto dura la visita?

- ¿Qué imagen, impresión y experiencia se llevan los visitantes del museo? (por ejemplo, ver libro de visitas, preguntar a los guías...)

- ¿Qué compran los visitantes en el museo? ¿Qué diferencias se observan?

- Además de visitar el museo, ¿qué otras actividades realizan los visitantes en la localidad del museo?

Estos aspectos han servido como esquema de trabajo en una de las líneas de conocimiento en el proyecto Dourotur (ver https://dourotur.utad.pt/) para conocer la función social de la red museística y patrimonial de la región del Douro (ver https://www.museudodouro.pt/redemuseus-douro). Creemos que puede servir de base reflexiva para convertir el museo etnológico en un laboratorio que integre las funciones de foro de debate y cuestionador crítico de los cambios sociales y culturales (cf. Arrieta, 2021). El museo etnológico como laboratorio significa que 
el museo es un centro de investigación sobre la realidad social y cultural, un buen vecino con sus próximos y también un lugar donde el conocimiento y los saberes sobre los patrimonios culturales se debaten, dialogan y comparten con los diferentes usuarios del museo.

\section{Referencias bibliográficas}

Alonso Fernández, L. (1993). Museología. Introducción a la teoría y práctica del museo. Madrid: Istmo.

Alonso Fernández, L. (1999). Introducción a la nueva museología. Madrid: Cátedra.

Arrieta, I. (ed.) (2021). Museos en transformación. Bilbao: Universidad del País Vasco.

Calvo Serraller, F. (1996). El Museo alejandrino. En: El museo, historia, memoria y olvido. Revista de Occidente, 177, 141-147.

Carvalho, A. (2011). Os Museus e o Património Cultural Imaterial. Estratégias para o desenvolvimento de boas práticas. Lisboa: Edições Colibri - CIDEHUS - Universidade de Évora.

Castro Seixas, P. (1997). Património, Museu e Dialogia. Trabalhos de Antropologia e Etnologia, $37(1-2), 21-40$.

Davis, P. (1999). Ecomuseum. A sense of place. London: Leicester University Press.

Fernández de Paz, E. (2003). "La museología antropológica ayer y hoy".. En: E. Fernández de Paz (Coord.), Antropología y Patrimonio: Investigación, Documentación e Intervención (pp. 30-47). Sevilla: IAPH (Instituto Andaluz de Patrimonio Histórico).

Hainard, J., Sabelli, F., Kaehr, R., Milliet, J., y Minkoff, G. (1989). Le salon de l'Ethnographie. Neuchâtel: Musée d’Ethnographie Neuchâtel.

Hooper-Greenhill, E. (1998). Los museos y sus visitantes. Gijón: Trea.

Hooper-Greenhill, E. (2000). Museums and the Interpretation of Visual Culture. Londres - New York: Routledge.

Iniesta I González, M. (1994). Els Gabinets del món. Antropologia, museus i museologies. Lleida: Editorial Argentviu.

Iniesta I González, M. (2002). "Museos y patrimonio cultural". En: VII Coloquio Galego de Museus. Santiago de Compostela: Colóquio Galego de Museus (comunicación no publicada).

Johnson, P., y Thomas, B. (1992). Tourism, Museums and the Local Economy. The Economic Impact of the North of England Open Air Museum at Beamish. Aldershot: Edward Elgar.

Kirshenblatt-Gimblett, B. (1998). Destination Culture. Tourism, Museums, and Heritage. Berkeley: University of California Press.

Kirshenblatt-Gimblett, B. (2001). La cultura de les destinacions: teoritzar el patrimony. Revista de Etnologia de Catalunya, 14, 44-61.

Lévi-Strauss, Cl. (1973). Antropología Estructural. Buenos Aires: Eudeba.

Lorente Lorente, J. P. (2006). Nuevas tendencias en teoría museológica: a vueltas con la museología crítica. Museos.es, 2: 24-33. 
Llopart, D. (1994). Patrimoni etnològic versus museus etnològics. Aixa: Revista Anual del Museu Etnològic del Montseny, La Gabella, 6, 7-14.

Lumley, L. (Ed.) (1988). The Museum Time-Machine. London: Routledge.

Marstine, J. (2006). New Museum Theory and Practice. London: Blackwell.

Nabais, A. (1984). Museologia, museografia, museus... Centro de Arqueología de Almada, 3, 44-45.

Pais de Brito, J. (2006). Patrimónios e identidades. A difícil construção do presente. E. Peralta, E. y M. Anico (Orgs.), Patrimónios e identidades. Ficções Contemporâneas (pp. 43-51). Oeiras: Celta.

Pereiro, X. y Vilar, M. (2002). "Autoimágenes y heteroimágenes en los museos etnográficos gallegos". En: AA.VV. (ed.), Actas del IX Congreso de Antropología de la Federación de Asociaciones de Antropología del Estado Español, Barcelona: Universidad de Barcelona - FAAEE.

Pereiro, X. (2009). Turismo cultural. Uma visão antropológica. La Laguna (Tenerife): PASOS. Recuperado de http://www.pasosonline.org/es/colecciones/pasos-edita/36-numero-2-turismo-cultural

Pomian, K. (1996). "Nation et patrimoine". En: D. Fabre (Ed.), L'Europe entre cultures et nations (pp. 8595). Paris: Editions de la Maison des sciences de l'homme.

Prat, J., y Comelles, J. M. (1993). La noción de patrimonio. En: Grupo de trabajo sobre la Recomendación de la UNESCO para la salvaguarda de la cultura tradicional y popular. Madrid: Ministerio de Cultura.

Rivière, G. H. (1989). La museología: curso de museología, textos y testimonio. Madrid: Akal.

Roigé, X. (2007). La reinvención del museo etnológico. I. Arrieta (Ed.), Patrimonios culturales y museos: Más allá de la historia y del arte (pp. 19-42). Bilbao: Euskal Erriko Unibertsitatea.

Segalem, M. (2003). "Cuestiones de identidad y alteridad. La experiencia francesa del patrimonio". En: J. A. González Alcantud, J. A. (Ed.), Patrimonio y pluralidad. Nuevas direcciones en antropología patrimonial (pp. 41-62). Granada: Centro de Investigaciones Etnológicas Angel Ganivet.

Simard, C. (1989). L'économuséologie: Comment rentabiliser une entreprise culturelle. Montréal: Centre éducatif et culturel.

Simard, C. (1991). Le patrimoine au temps présent: les économusées. Cap-aux-Diamants: la revue d'histoire du Québec, 25, 64-66.

Valdés Sagués, Maa del C. (1999). La difusión cultural en el museo: Servicios destinados al gran público. Gijón: Trea.

Walsh, K. (1992). The representation of the past: museum and heritage in the post-modern world. London: Routledge.

Witcomb, A. (2003). Re-Imagining the Museum. Beyond the Mausoleum. London: Routledge. 